\title{
Research on Mechanical Properties of Nano-modified Epoxy Resin Color Anti-skid pavement Materials
}

\author{
Yongqiang Zhong ${ }^{1 *}$ \\ ${ }^{1 *}$ Transportation College, Huaiyin Institute of Technology, Huai'an, 223003, China
}

\begin{abstract}
By referring to the domestic and foreign researches on color anti-skid pavement, the composition of epoxy resin coating material for color antiskid pavement is designed. The purpose of the experiment is to analyze the effect of nano-modified epoxy resin coating by adding $2.5 \%$ nano-organic montmorillonite modifier to the existing color anti-skid pavement surface material. Test and compare the change of mechanical properties of nano-modified epoxy resin coating binder before and after nano-modified. Then the effect of nano-modification is analyzed.
\end{abstract}

\section{Introduction}

The color anti-skid pavement refers to the traffic road which is used in municipal or highway brake deceleration area and needs the surface anti-skid coefficient to play the color warning and anti-skid double function, which is beautiful and safe[1-2]. In this paper, organic nano-montmorillonite is selected as modifier, which can effectively improve the bond strength, stability and toughness of the composite. The mechanical properties of color epoxy resin coating material for anti-skid road surface before and after nano-modification were tested.

\section{Composition of color epoxy resin coating material for anti-skid pavement surface}

\subsection{The main agent}

Epoxy resin is a kind of binder for color anti-skid pavement surface. It has excellent anti-aging performance and strong adhesion, which can make color anti-skid road surface play a good role. This experiment uses an epoxy resin which is specially applied to the color anti-skid pavement surface. Its appearance is transparent viscous liquid.

\subsection{Curing agent}

The epoxy resin curing agent used in this test is the T-31 curing agent. It is made of a variety of compounds. However, it can effectively improve the impact resistance and shear strength of the products when curing epoxy resin. It is widely used in the coating industry.

\subsection{Nano modifier}

Organic nano montmorillonite and its microstructure diagram are shown in Figure 1 and Figure 2.

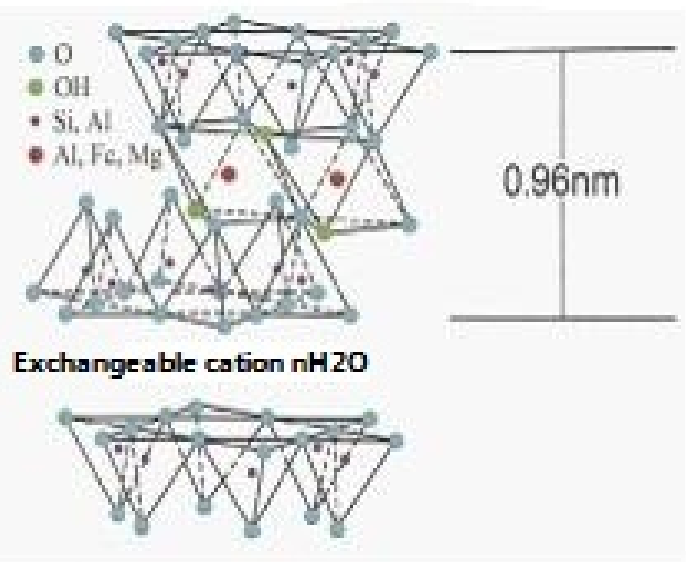

Figure1. Microstructure diagram of montmorillonite

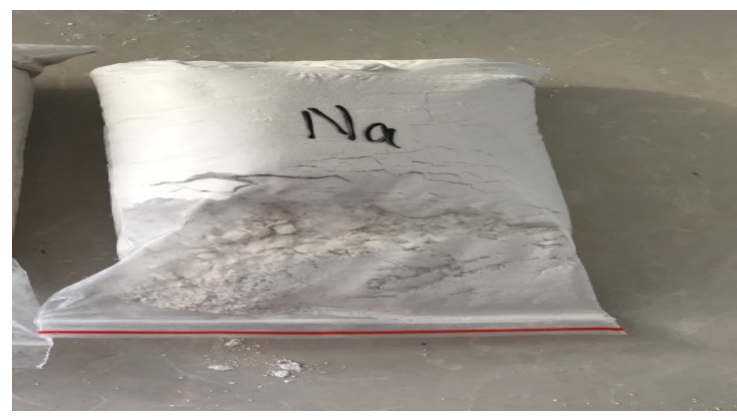

Figure2. Organic nano montmorillonite

Organic nano-montmorillonite (OMMT) is a lamellar silicate (Figure 1). The main component is montmorillonite and the cations in its lamellar structure

\footnotetext{
*Corresponding author: zyqjlu@126.com
} 
are easy to exchange with the ions in the external environment, so that it has a strong ability to absorb other substances and uniform distribution and can effectively improve the indicators of polymerization products. The modifier selected in this experiment is sodium-based organic nano-montmorillonite [3] (Figure 2).

\section{Chemical principle analysis and preparation of epoxy resin nano-modified coating materials}

\subsection{Chemical Principle}

The curing reaction process of epoxy resin is shown in Figure 3.

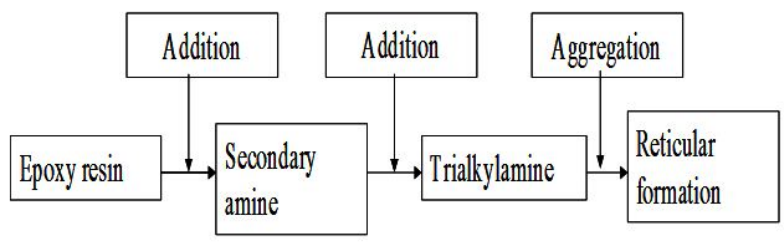

Figure 3. Curing reaction process of epoxy resin

\subsection{Preparation Process}

\subsubsection{Experimental instruments and drugs}

Epoxy monomer, epoxy resin curing agent T-31, organic nano Montmorillonite, cone flask, spoon, glass rod, electronic scale, booster electric mixer, constant temperature water bath box.

\subsubsection{Adding nano-modifier}

It is necessary to mix the modifier organic nano-montmorillonite with the epoxy resin in advance, and then add the curing agent T-31[4-5].

\subsubsection{Polymerization}

Mix the epoxy with the curing agent in a ratio of 7:3. The epoxy resin began to solidify at $1 \mathrm{~h}$ and form the epoxy resin $2 \mathrm{~h}$ later. However, the curing reaction will continue, and the epoxy resin will completely solidify at about 48 h.

\subsection{Proportion composition of modifier}

According to the specific situation of the experiment, with the increase of OMMT dosage, the fluidity of the material will become worse in Table 1 , which is not conducive to the construction on site. The optimal dosage of OMMT is $2.5 \%$, that is $100 \mathrm{~g}$ epoxy resin needs to add $2.5 \mathrm{~g}$ OMMT modifier.
Table 1. OMMT dosage ratio experiment in epoxy resin modification

\begin{tabular}{cccc}
\hline $\begin{array}{c}\text { Epoxy } \\
\text { resin mass } \\
(\mathrm{g})\end{array}$ & $\begin{array}{c}\text { OMMT mass } \\
\text { percentage } \\
(\%)\end{array}$ & $\begin{array}{c}\text { OMMT } \\
\text { mass }(\mathrm{g})\end{array}$ & Reactive state \\
\hline 100 & 2.0 & 2.00 & Fully dissolved \\
100 & 2.5 & 2.50 & $\begin{array}{c}\text { Fully dissolved } \\
\text { Post-dissolution } \\
\text { precipitation }\end{array}$ \\
\hline
\end{tabular}

\subsection{Composition of curing agent ratio}

In order to determine the appropriate dosage of curing agent T-31 for epoxy resin, it is necessary to carry out the ratio experiment. The curing agent in different proportions is mixed with the epoxy resin and the curing time is recorded in Table 2.

Table 2. The dosage ratio of epoxy resin and curing agent T-31

\begin{tabular}{cccc}
\hline $\begin{array}{c}\text { Epoxy resin } \\
\text { resin:T-31 }\end{array}$ & $\begin{array}{c}\text { Epoxy resin } \\
\text { mass }\end{array}(\mathrm{g})$ & $\begin{array}{c}\mathrm{T}-31 \\
\text { mass }\end{array}(\mathrm{g})$ & $\begin{array}{c}\text { Curing time } \\
(\mathrm{h})\end{array}$ \\
\hline $1: 1$ & 50 & 50 & 0.48 \\
$6: 4$ & 60 & 40 & 0.54 \\
$7: 3$ & 70 & 30 & 0.67 \\
$8: 2$ & 80 & 20 & 0.86 \\
$9: 1$ & 90 & 10 & 1.43 \\
\hline
\end{tabular}

Although the curing time of epoxy resin is shortened with the increase of curing agent proportion, the curing time of epoxy resin is very short when the curing agent proportion is high, which is not conducive to the construction operation. However, the curing time is too long when the curing agent proportion is too low, which affects the traffic opening. Therefore, the proportion of curing agent selected in this experiment is 7:3.

\section{Drawing test of color anti-skid pavement coating material}

\subsection{Experimental Instrument}

The test instruments used in the drawing test and the prepared specimens are shown in Figure 4 and Figure 5. 


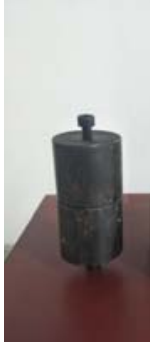

Figure 4. Specimen

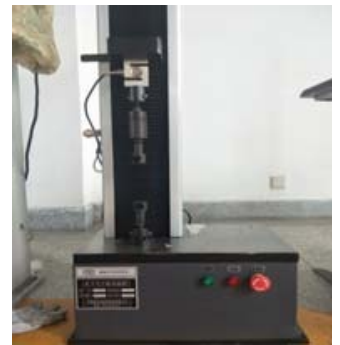

Figure 5 .Drawing instrument

\subsection{Experimental steps}

Six sets of standard cylindrical test blocks are prepared. Each circular test column has a standard diameter of 50 $\mathrm{mm}$. One end is a hard and smooth surface that can be applied with the adhesive that needs to be measured. The other end of the hook can be connected to the tensile testing machine. Before the test, the test block should be cured for $24 \mathrm{~h}$ at a temperature of $20^{\circ} \mathrm{C}$ and $90 \%$ humidity under standard conditions. Connect the cured specimen with the drawing instrument and fix the drawing speed at $2 \mathrm{~mm} / \mathrm{min}$. When the specimen is broken, the experiment stops and the computer automatically records the data. The tensile strength can be calculated by formula (1).

$$
\sigma=\frac{F}{A}
$$

Where: F-- Destructive power $(\mathrm{N})$;

A-- Test column area $\left(\mathrm{mm}^{2}\right)$;

$\sigma$--Tensile strength (Mpa).

\subsection{Tensile strength before and after nano modification of epoxy resin coating material for color anti-skid pavement}

At present, modification mainly includes two aspects: modification of epoxy resin monomer and modification of curing agent. Color antiskid pavement coating materials must have good tensile properties to ensure good adhesion and life in use.In this paper, modification of epoxy resin monomer is selected to improve its tensile strength.Tensile strength of epoxy resin coating materials before nano modification is shown in Table 3 and tensile strength of epoxy resin coating materials after nano modification is shown in Table 4. When bonding the specimen, the center of the upper and lower two specimens should be fully aligned to avoid low experimental results.

Table 3. Tensile strength of epoxy resin coating materials before nano modification

\begin{tabular}{ccc}
\hline $\begin{array}{c}\text { The serial } \\
\text { number }\end{array}$ & $\begin{array}{c}\text { Destructive power } \\
(\mathrm{N})\end{array}$ & $\begin{array}{c}\text { Tensile strength } \\
(\mathrm{MPa})\end{array}$ \\
\hline 1 & 2377.87 & 1.21 \\
2 & 2565.32 & 1.31
\end{tabular}

$\begin{array}{ccc}3 & 2374.12 & 1.21 \\ 4 & 2389.45 & 1.22 \\ 5 & 2405.02 & 1.23 \\ 6 & 2436.02 & 1.24 \\ & & 1.24 \\ \begin{array}{c}\text { The average } \\ \text { value }\end{array} & 2424.63 & \end{array}$

Table 4. Tensile strength of epoxy resin coating materials after nano modification

\begin{tabular}{ccc}
\hline $\begin{array}{c}\text { The serial } \\
\text { number }\end{array}$ & $\begin{array}{c}\text { Destructive power } \\
(\mathrm{N})\end{array}$ & $\begin{array}{c}\text { Tensile strength } \\
(\mathrm{MPa})\end{array}$ \\
\hline 1 & 2765.23 & 1.41 \\
2 & 2801.42 & 1.43 \\
3 & 2794.89 & 1.42 \\
4 & 2744.19 & 1.40 \\
5 & 2821.05 & 1.44 \\
6 & 2785.69 & 1.42 \\
& 2785.41 & 1.42 \\
\hline $\begin{array}{c}\text { The average } \\
\text { value }\end{array}$ & & \\
\hline
\end{tabular}

Epoxy resin material before modification can withstand the maximum average value of $2424.63 \mathrm{~N}$, the average tensile strength of $1.24 \mathrm{Mpa}$ (Table 3). After adding $2.5 \%$ organic montmorillonite it is found that the epoxy resin material can withstand the most average value of $2785.41 \mathrm{~N}$, the average tensile strength of 1.42 Mpa (Table 4). Tensile strength increased by $14.5 \%$ (Figure 6).

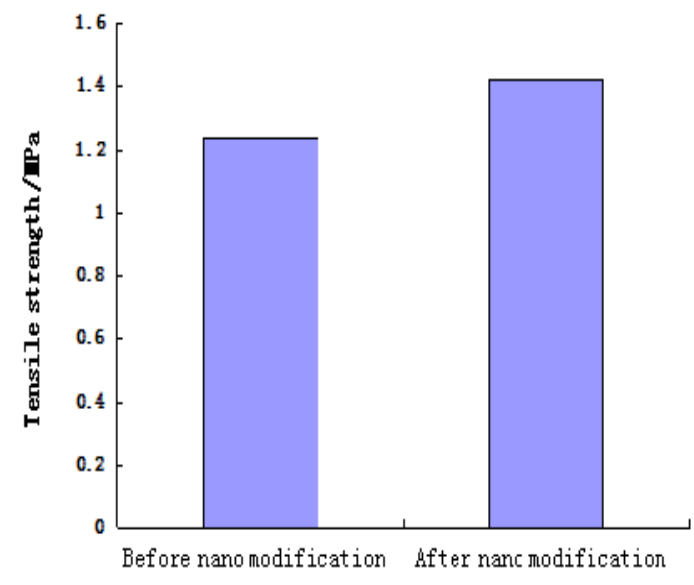

lodified st ate of epoxy resin

Figure 6. Comparison of tensile failure strength of epoxy resin coating materials before and after nano modification

This indicates that nano-materials have unique physical and chemical effects.The organic 
nano-montmorillonite has a great adsorption to organic compounds and can effectively improve the bonding strength of composites. The modified epoxy resin tensile mechanical properties significantly enhanced. Epoxy resin itself also has good physical and chemical properties, excellent bonding strength on the surface of metal and non-metal materials, good stability, high hardness and flexibility. Epoxy resin as the matrix of composite materials has a great application prospect.

\section{Conclusion}

This indicates that the nano-organic montmorillonite modification can effectively improve the tensile properties of epoxy resin. Tensile strength increased by $14.5 \%$ after adding $2.5 \%$ nano-organic montmorillonite modifier to the existing color anti-skid pavement surface material. At the same time, according to the investigation, most of the epoxy resin materials used in the color anti-skid road surface are modified by curing agent to make its tensile strength meet the requirements.

The optimal dosage of OMMT is $2.5 \%$, that is $100 \mathrm{~g}$ epoxy resin needs to add $2.5 \mathrm{~g}$ OMMT modifier. The curing time of epoxy resin is very short when the curing agent proportion is high, which is not conducive to the construction operation. However, the curing time is too long when the curing agent proportion is too low, which affects the traffic opening. Therefore, the proportion of curing agent selected in this experiment is $7: 3$. It is necessary to mix the nano-organic montmorillonite with the epoxy resin in advance, and then add the curing agent $\mathrm{T}-31$.

Increasing the research strength of color antiskid pavement materials, enhancing the mechanical properties and construction level, the application of new nano modified color antiskid pavement technology can effectively solve the problem of color antiskid pavement in the application process. Bus lanes, intersections of vehicles starting and stopping places, sidewalk sections and other sections with more traffic flow can be applied nano - modified anti-skid coating materials for color antiskid pavement laying. The next few years in the Asia-Pacific region of the anti-skid coating market will continue to grow and expand.

\section{References}

1. Xue Changlong, Cao Yuhua, LI Changjiang, Liu Hengquan, Liu Xingsheng, Zhou Ronggui. Development and performance research of environmentally friendly color anti-skid pavement materials $[\mathrm{J}]$. Highway traffic science and technology (applied technology edition),2017,13(04):119-122.

2. Bai yunqi, Xue Limei. Advances in modification of epoxy resins [J]. Chemistry and adhesives, 2007,29 (4): 289.

3. Mao Shuhong, Wang Runping, WANG Yan, Liu Jun, Duan Xiuqin. Research progress of nano montmorillonite composites in coatings [J].
Liaoning chemical industry,2010,39(11):1162-1165.

4. Shang Wulin. Study on modified Epoxy resin nanocomposite by Starch nanocrystalline [J]. Anhui chemical industry, 2012,38 (4) : 38-45.

5. Liu Yashu, Wang Rong. Chemical Technology and Development [J], 2016,45 (07) :22-24. 